\title{
Ungulate behavioral responses to the heterogeneous road-network of a touristic protected area in Africa
}

Article

Accepted Version

Mulero-Pázmány, M., D'Amico, M. and Gonzalez-Suarez, M. (2016) Ungulate behavioral responses to the heterogeneous road-network of a touristic protected area in Africa. Journal of Zoology, 298 (4). 233- 240. ISSN 1469-7998 doi: https://doi.org/10.1111/jzo.12310 Available at https://centaur.reading.ac.uk/51611/

It is advisable to refer to the publisher's version if you intend to cite from the work. See Guidance on citing.

Published version at: http://dx.doi.org/10.1111/jzo. 12310

To link to this article DOI: http://dx.doi.org/10.1111/jzo.12310

Publisher: Zoological Society of London

All outputs in CentAUR are protected by Intellectual Property Rights law, including copyright law. Copyright and IPR is retained by the creators or other copyright holders. Terms and conditions for use of this material are defined in the End User Agreement.

www.reading.ac.uk/centaur 
Central Archive at the University of Reading

Reading's research outputs online 


\section{Title}

Ungulate behavioral responses to the heterogeneous road-network of a touristic protected area in Africa

\section{Authors}

Margarita Mulero-Pázmány ${ }^{1,2}$, Marcello D’Amico ${ }^{3,4}$, Manuela González-Suárez ${ }^{3,5}$

All authors contributed equally

\section{Affiliations}

1. Department of Evolutionary Ecology, Doñana Biological Station, CSIC, Seville, Spain.

2. Department of Natural Sciences, Universidad Técnica Particular de Loja, San Cayetano Alto, Loja, Ecuador.

3. Department of Conservation Biology, Doñana Biological Station, CSIC, Seville, Spain.

4. Department of Biology of Organisms and Systems, University of Oviedo, Oviedo, Spain.

5. Ecology and Evolutionary Biology, School of Biological Sciences, University of Reading, Whiteknights, Reading, Berkshire, RG6 6AS, UK

*Corresponding author:

Margarita Mulero-Pázmány

Department of Evolutionary Ecology, Doñana Biological Station, CSIC

Calle Américo Vespucio s/n. 41092 Seville, Spain

E-mail: muleromara@ebd.csic.es, muleromara@hotmail.com

Short title: Road impacts on African ungulates. 


\begin{abstract}
Understanding how wildlife respond to roads and traffic is essential for effective conservation. Yet, not many studies have evaluated how roads influence wildlife in protected areas, particularly within the large iconic African National Parks where tourism is mainly based on sightings from motorized vehicles with the consequent development and intense use of roads. To reduce this knowledge gap we studied the behavioral response and local spatial distribution of impala Aepyceros melampus along the heterogeneous (with variation in road surface type and traffic intensity) road-network of Kruger National Park (KNP, South Africa). We surveyed different types of roads (paved and unpaved) recording the occurrence of flight responses among sighted impala and describing their local spatial distribution (in relation to the roads). We observed relatively few flight responses (19.5\% of 118 observations), suggesting impalas could be partly habituated to vehicles in KNP. In addition, impala local distribution is apparently unaffected by unpaved roads, yet animals seem to avoid the close proximity of paved roads. Overall, our results suggest a negative, albeit small, effect of traffic intensity and of presence of pavement on roads on the behavior of impala at KNP. Future studies would be necessary to understand how roads influence other species, but our results show that even within a protected area that has been well-visited for a long time, wildlife can still be affected by roads and traffic. This result has ecological (e.g., changes in spatial distribution of fauna) and management implications (e.g., challenges of facilitating wildlife sightings while minimizing disturbance) for protected areas where touristic activities are largely based on driving.
\end{abstract}

Keywords: African ungulates, anti-predator behavior, barrier effect, impala Aepyceros melampus, road impact, road avoidance, traffic avoidance, vehicle avoidance. 


\section{Introduction}

The worldwide development of road-networks and associated motorized traffic can greatly impact natural populations (Laurance et al., 2014), a fact that has attracted the attention of conservation biologists leading to the rise of a discipline called road ecology (Trombulak \& Frissell, 2000). The presence of roads can alter natural habitats and threat biodiversity through noise, light and chemical pollution, habitat destruction, disruption of communities and facilitation of biological invasions (Forman \& Alexander, 1998; D’Amico et al., 2013). The most widely-acknowledged road impacts for wildlife are vehicle-collision mortality and barrier effects (Conover et al., 1995; Gagnon et al., 2007) which are both consequence of an individual's choice to cross or avoid a road (Jaeger et al., 2005; Grilo et al., 2012). Specifically, barrier effects include the behavioral responses towards the road structure itself (road avoidance), the associated emissions (traffic avoidance) and/or the immediate disturbances (vehicle avoidance; D’Amico et al., in press; Jaeger et al., 2005). These behavioral responses can change animal movement patterns (Cole, Pope \& Anthony, 1997), fragmenting large and connected populations into small isolated ones (Vos \& Chardon, 1998), and eventually compromising their persistence (Carr \& Fahrig, 2001). Despite these potential effects, relative tolerance to motorized traffic has been observed in roads with frequent traffic, especially within protected areas (Wilmers et al., 2003). This sort of habituation can be beneficial in the case of touristic areas by improving visibility of wildlife for visitors. However, habituation can present risks for both human and animals by increasing human-wildlife interactions which can lead to greater risk of wildlife attacks (Hubbard \& Nielsen, 2009), road-associated mortality of protected species (Knapp, 2004), and increasing poaching risks near roads (Papaioannou \& Kati, 2007).

Although there is a growing body of literature on barrier effect and road tolerance (Fahrig \& Rytwinski, 2009), there are still significant gaps in our understanding of how 
heterogeneous road-networks (i.e., those with variation in road substrates and associated traffic intensity) can affect wildlife. Heterogeneous road-networks are frequently found within rural and natural landscapes where wildlife is often more abundant and road impacts can be more severe (D’Amico et al., in press; Forman \& Alexander, 1998). Few studies of road ecology have been conducted along road-networks in protected areas, even though in many protected areas human activities are centered on wildlife sightings from motorized vehicles, with the associated development of road-networks and traffic. Understanding road effects in these areas is critical for effective wildlife conservation, human safety and tourism-related economy (Hubbard \& Nielsen, 2009; Malo, Acebes \& Traba, 2011).

This study aims to improve our understanding of the behavioral responses of ungulates to a heterogeneous road-network in an African protected area. Previous works of road effects in Africa have mainly focused on rainforest habitats (e.g. Laurance et al., 2006) with few studies in more open areas (but see Newmark et al. 1996; Ndibalema et al. 2007) despite the fact that many emblematic African parks are largely open-habitats. To address this gap, we conducted a study in Kruger National Park (KNP hereinafter), which is one of the main touristic attractions of South Africa. In particular, we studied the prevalence of flight responses and the local spatial distribution of impalas Aepyceros melampus in relation to different types of roads with different traffic intensities, accounting also for other potentially important factors (i.e., herd size in Stankowich, 2008; Périquet et al., 2010; Malo et al., 2011). We particularly focused on impala because it is an abundant species (estimated current KNP population is 132,300 - 176,400 individuals; KNP Scientific Services, 2015). Although not a conservation target (listed as "least concern" by the IUCN;IUCN SSC Antelope Specialist Group, 2008), it plays an important ecological role in the African savannah (Pienaar, 1969; Hayward \& Kerley, 2008). Overall, our study aims to improve our understanding of how wildlife responds to roads and traffic. This knowledge can contribute to 
more effective conservation strategies, as well as improved management of touristic activities within protected areas, particularly those in which motorized tourism is prevalent.

\section{Methods}

Study area

Kruger National Park $\left(22^{\circ} 15^{\prime} \mathrm{S}-25^{\circ} 32^{\prime} \mathrm{S} ; 30^{\circ} 50^{\prime} \mathrm{E}-32^{\circ} 02^{\prime} \mathrm{E}\right)$ is one of the largest reserves in Africa (nearly 20,000 $\mathrm{km}^{2}$ ) and part of the Great Limpopo Transfrontier Park. It has a subtropical climate with hot-humid summers (October-April) and warm-dry winters (May-September) and encompasses diverse, mostly open habitat ecozones (Gertenbach 1983). The first vehicle entered KNP in 1927 and currently there are approximately 2,300 km of roads ( 850 of which are paved), which are used by over 1.5 million motorized visitors per year (http://www.sanparks.org/parks/kruger/all.php). Our study was conducted in the central part of KNP, between the Letaba and Skukuza camps (Fig. 1).

\section{Data collection and variables definition}

Impala behavior was studied during April-May 2014 along 12 transects (average length of $18 \mathrm{~km}$ ) located on six paved and six unpaved roads (Fig. 1). Observations were gathered from a high-clearance $4 \times 4$ vehicle driving at $<30 \mathrm{~km} / \mathrm{h}$ between 08:00 and 17:00 $\mathrm{h}$. While sampling a transect, two observers searched for impala individuals or herds located $<300 \mathrm{~m}$ from each side of the road (our range of detection). A third observer noted the number of vehicles circulating in the opposite direction. The number of counted vehicles over the duration of the sampling was used to estimate the number of vehicles per minute as a measurement of traffic intensity on the surveyed road. When herds were sighted, we selected a focal individual (the individual located closest to the road when the herd was first sighted), and estimated herd size (minimum group size because some individuals in large herds could 
have been out of sight). For each sighting we recorded the position of our vehicle using a GPS (Garmin GSPMAP 62, KS, USA).

We evaluated impala behavior on each sighting using two response variables: 1) flight response and 2) tolerance distance. We recorded the occurrence of a flight response (binary variable) when the focal individual moved rapidly away from the road as a reaction to our approaching vehicle (i.e., vehicle avoidance). We did not consider an individual had fled if it did not move or moved parallel or towards the road. Tolerance distances were defined as the perpendicular distance to the road (directness estimate sensu Bulova, 1994) of focal individuals engaged in stationary behavior (not involving prolonged directional movements, not fleeing or travelling). Distances were estimated using a Leica Rangemaster 1200 CRF-M rangefinder by approaching the focal individual as close as possible while staying on the road. Observed tolerance distances may exceed the minimum at which individuals could tolerate vehicles, because we could not continue to approach individuals until they flee. Animals that "tolerated" vehicles could have still perceived the vehicle and possibly experienced stress. If the focal animal had a stationary behavior when we approached, we directly estimated its tolerance distance. If it was travelling when first sighted or fled during our approach, we waited until its behavior became stationary to estimate the tolerance distance. If the individual moved out of sight, no tolerance distance was recorded. Additionally, for focal animals that were stationary upon first sight but subsequently travelled or fled during our approach, we also estimated the initial distance (perpendicular distance to the road from the location at which the individual was first sighted) using reference points. For focal animals that did not move, the initial and tolerance distances were the same.

Because detectability of impala and behavioral responses may differ between habitat types, we identified the ecozone for each sighting based on a simplified version of the KNP landscapes (originally described by Gertenbach 1983) which includes five different categories 
(Table S1). Ecozones were assigned to georeferenced sighting locations using the ecozone GIS layer available from Sanparks (2014) with ArcGIS 9.4.

\section{Data analysis}

We evaluated the effects of road type and traffic on both recorded responses (flight response and tolerance distance) fitting generalized linear mixed models (GLMMs). Flight responses (present or absent) were modeled with GLMMs fitted with a binomial family (logit link). Tolerance distances were transformed $\left(\log _{10}[\mathrm{x}+1]\right)$ and modeled with LMM (Gaussian family, identity link). Models were fitted with the functions glmer and lmer from the lme4 package (version 1.1-7) in R 3.1.1 (R Core Team 2014). Models included as predictors either road surface (categorical factor with two levels: paved or unpaved) or traffic intensity (estimated as the observed number of incoming vehicles per min.), with herd size as a covariate (standardized by subtracting the mean and dividing by the standard deviation). Because road surface and traffic intensity are correlated, we could not fit a model including both variables as predictors to assess their potentially differential roles. To control for potential differences in detectability of impala and response patterns across roads, days, and vegetation zones, fitted models included the transect identifier (nested within date) and the ecozone as random effects. We evaluated model residuals to determine if model assumptions were met. Autocorrelation plots (function acf), and variograms (function variog of the library geoR in R,Ribeiro \& Diggle, 2001) were used to detect evidence of temporal or spatial autocorrelation in model residuals. We calculated $95 \%$ confidence intervals of predicted values using bootstrap percentiles based on 5,000 replicates (using the function confint in $\mathrm{R}$ ). P-values were estimated with likelihood ratio tests. Model fit was described using $\mathrm{R}_{\mathrm{c}}^{2}$ representing the variation explained by both fixed and random factors; and $\mathrm{R}_{\mathrm{m}}^{2}$ represents the variation explained by the fixed factors only (Nakagawa and Schielzeth 2013). These $\mathrm{R}^{2}$ 
values were estimated using the function r.squaredGLMM from the package MuMIn (Barton 2013) in R.

Finally, we evaluated how the observed local spatial distribution (distance to the road) from each road surface differed from the expected in a hypothetical no-road situation. As we could not drive off-road to observe impala spatial distribution away from roads, we compared the observed distribution of initial distances in paved and unpaved roads $v s$. the expected distribution under a null model. The null model assumes impala are randomly distributed in relationship to roads (i.e., roads do not affect local spatial distribution) and are detected with a probability that decreases with distance, following a negative exponential distribution curve, which is a commonly used detectability function (Thomas et al., 2002). The rate parameter of the exponential curve was defined as the reciprocal of the observed global mean initial distance (rate $=0.023$ ), thus assuming a common function for all roads. We then used the function rexp in $\mathrm{R}$ to define expected initial distances for 10,000 random samples of 54 and 61 observations (reflecting the available data from paved and unpaved roads, respectively). Using these random samples we estimated the probability that observed distance distributions could have occurred if the null model (a hypothetical no-road situation) was true.

\section{Results}

We observed impala on 54 occasions driving a total of $141 \mathrm{~km}$ along paved roads (an average of 3.8 impala observations $/ 10 \mathrm{~km}$ ), and on 64 occasions along $81 \mathrm{~km}$ of unpaved roads (7.7 observations/10 km. Full dataset available as Table S1). Impalas were found in herds with a mean size of 8.6 individuals $(\mathrm{SD}=14.49)$ although observations of solitary individuals were common (42.6\% in paved roads and 51.6\% in unpaved roads). Based on our estimate of traffic intensity, paved roads had more traffic (mean=0.60 vehicles/min, 
$\mathrm{SD}=0.349$ ), with on average six times more vehicles per minute, than unpaved roads (mean $=0.10, \mathrm{SD}=0.077)$.

We detected relatively few flight responses (23 out of 118 observations) with more responses in unpaved roads (15 out of 64$)$ compared to paved roads ( 8 out of 54$)$. However, we found no evidence of a significant effect of road surface on the probability of flight response $(\mathrm{n}=117 ; \mathrm{F}=1.04, \mathrm{P}=0.32$; controlling for herd size: regression coefficient $\beta=-0.65$, $\mathrm{SE}=0.446, \mathrm{P}=0.064 . \mathrm{R}_{\mathrm{m}}^{2} \approx \mathrm{R}_{\mathrm{c}}^{2}=0.12$ ). Similarly, we found no effect of traffic intensity on the probability of flight response $(\mathrm{n}=117 ; \beta=-1.12, \mathrm{SE}=0.820, \mathrm{P}=0.150$; herd size $\beta=-0.66$, $\left.\mathrm{SE}=0.448, \mathrm{P}=0.064 . \mathrm{R}_{\mathrm{m}}^{2} \approx \mathrm{R}_{\mathrm{c}}^{2}=0.15\right)$. Instead, individuals that fled were significantly closer to the road (mean $30.5 \mathrm{~m}$, range 0-154) than those that did not respond (mean $35.0 \mathrm{~m}$, range 0215. Initial distance $\beta=-1.12, \mathrm{SE}=0.455, \mathrm{P}=0.012$; herd size $\beta=-0.68, \mathrm{SE}=0.437, \mathrm{P}=0.047$, $\mathrm{R}_{\mathrm{m}}^{2}=0.18$ and $\left.\mathrm{R}_{\mathrm{c}}^{2}=0.19 ; \mathrm{n}=114\right)$. Among the individuals that showed flight response, 12 fled out of sight and the remaining 11 moved an average of $12 \mathrm{~m}$ (range: $3-23 \mathrm{~m}$ ).

We estimated tolerance distances on 114 occasions (52 observations from paved roads and 62 from unpaved roads, table S1). Tolerance distances were an estimated $14.7 \mathrm{~m}$ greater on paved roads compared to unpaved roads $(\mathrm{F}=9.20, \mathrm{P}=0.008$. Fig. 2$)$, with larger herds generally closer to the road (regression coefficient $\beta=-0.08, \mathrm{SE}=0.039, \mathrm{P}=0.037$. Model $\mathrm{R}_{\mathrm{m}}^{2}=0.10$ and $\mathrm{R}_{\mathrm{c}}^{2}=0.23$ ). Fitting an interaction term between herd size and road surface did not improve model fit (interaction term $\mathrm{F}=0.03, \mathrm{P}=0.854$ ) suggesting the effect of herd size was similar in both paved and unpaved roads. Tolerance distances also increased with traffic intensity $(\beta=0.42, \mathrm{SE}=0.132, \mathrm{P}=0.007)$ controlling for the influence of herd size $(\beta=-0.09$, $\mathrm{SE}=0.038, \mathrm{P}=0.029$. Model $\mathrm{R}_{\mathrm{m}}^{2}=0.12, \mathrm{R}_{\mathrm{c}}^{2}=0.29$. Fig. 3 ). Evaluation of model residuals indicated that model assumptions were met with no evidence of temporal or spatial autocorrelation. 
Finally, we compared the observed impala local spatial distribution with a null model that assumed roads did not influence distribution locally. Observed initial distances in unpaved roads did not depart from the expected under the null model: observed frequencies were within the $95 \%$ confidence intervals of the distribution of expected frequencies (Fig. 2). However, observed distances in paved roads deviated from the expected with an unlikely low number of sightings within the first 10 meters (Fig. 2). If the null model were true the probability of having only six sightings at this distance would be $<0.06$, suggesting impala may be avoiding the areas closest to paved roads.

\section{Discussion}

Our study is the first assessment of ungulate behavioral responses towards roads and traffic at Kruger National Park, an emblematic touristic park in Africa, offering insights into the complexity of wildlife responses to heterogeneous road-networks within protected areas. In particular, we found evidence that impala change their local spatial distribution near paved and well-travelled roads. Nevertheless, our results also suggest habituation may exist given the limited flight responses observed (19.5\%) and the relatively short average distance at which impalas fled from the vehicle $(30.5 \mathrm{~m})$ compared to distances registered for other ungulates (e.g., $132 \mathrm{~m}$ in Papouchis, Singer \& Sloan, 2001). Habituation would not be unexpected in KNP given that cars have been regularly present for $>50$ years, and impala and other ungulate species have been shown to exhibit habituation in other protected areas (Setsaas et al., 2007; Stankowich, 2008; Malo et al., 2011). However, it is important to note that individuals may experience stress even if flight responses are not observed; thus even apparently habituated animals may be affected by human disturbances (Herrero et al., 2005).

Our results show that the local spatial distribution of impala is largely unaffected by unpaved roads although animals apparently avoid close proximity (first $10 \mathrm{~m}$ ) to paved roads. 
This distance is relatively short compared to edge effects reported for other ungulate species that range from 50 to 2800 meters (Alves \& Bager, 2013), but could reflect a traffic-induced landscape of fear which should be further studied (Laundré, Hernández \& Altendorf, 2001; Ciuti et al., 2012). As mentioned above, impala at KNP may exhibit partial habituation to vehicles, which could reduce the avoidance of linear infrastructures. Studies of impala in other areas have reported both no evidence of road/traffic avoidance (Newmark et al., 1996) and a tendency to avoid major roads (Mtui, 2014). Differences in response may be explained by different methodologies or because different habitat features, histories of exposure to roads and traffic patterns modulate impala responses differently.

Avoidance of paved roads may be directly associated with the presence of pavement (i.e. road avoidance) or with higher traffic intensity. Based on our traffic estimates, paved roads at KNP have approximately six times more cars per minute than unpaved roads (see also Ferreira \& Harmse 1999). Unfortunately, in our study we could not disentangle the effect of road surface from associated traffic as both are highly correlated, a pattern often reported in studies of road ecology (Jaeger et al., 2005; D’Amico et al., 2015). Avoidance associated to road surfaces has been found in small-sized species such as amphibians and rodents (Merriam et al., 1989; McGregor, Bender \& Fahrig, 2008) but it has not been reported for ungulates. On the other hand, sensitivity to traffic has been suggested for impala based on observed changed in stress hormones (Lunde, 2013) and it has been detected in other ungulates (Creel et al., 2002; Stankowich, 2008; St. Clair \& Forrest, 2009). Future work would be necessary to differentiate the role of road surface $v s$. traffic on impala responses and to assess how these effects vary along time (Meisingset et al., 2013 detected that reed deer road avoidance is lower at night than during daylight).

Flight initiation distance (FID hereinafter, Stankowich, 2008) is the most commonly used indicator in disturbance studies, but it has been criticized (Dumont et al., 2012) because 
estimates can be affected by recent disturbances (i.e. a previous vehicle) and/or by missed responses if the animal detects the observer early. These confounding factors become especially relevant for comparisons in which the probability of earlier disturbances varies among the compared categories (e.g., recent disturbances are more likely in roads with more traffic). Although it is difficult to control for these effects, we propose here the use of tolerance distance because it reflects the distance at which a focal individual remains stationary after being exposed to a vehicle. We presume tolerance distance varies less than FID after an immediate previous disturbance, and therefore is more suitable to compare scenarios with different levels of disturbance. This indicator also presents the advantage of capturing information on the local spatial distribution from individuals that do not flee, and thus is more convenient for studying species with low flight response rates for which estimating FID would require very high sampling efforts and potentially result in greater disturbance.

Overall, this study shows that paved roads and traffic can modify the behavior and local spatial distribution of impala at KNP. However, our approach presented some limitations. First, we gathered all data driving on public roads; thus, we could not control the presence of other vehicles or study impala responses driving off-road. Second, by not being able to gather data on foot or using other approaches we could not disentangle the influence of our own vehicle from that of road surface or overall traffic on impala responses. The use of alternative methodologies to determine local spatial distribution, for example indirect cues (i.e. pellets surveys, bio-logging; Negrões et al., 2011), or Unmanned Aircraft Systems (Mulero-Pázmány et al., 2014) could help reduce observer interference. Despite these limitations, and even though KNP has been a protected area with regular presence of vehicles for a long time, we observed an effect of traffic and paved roads on impala, which raises a 
word of caution about possible ecological and management implications that may be relevant to other species or areas.

Managers of touristic protected areas have the difficult mission of keeping a sustainable balance between protecting biodiversity, satisfying visitors and optimizing the profitability of the park. In this study we found that although impala may be partly habituated, high traffic intensity and pavement could lead to barrier effects. For instance, we recorded twice as many impala observations per driven $\mathrm{km}$ in unpaved roads compared to paved roads, and impala were sighted further from paved roads, which are those most often used by tourists (Ferreira \& Harmse, 1999). This potential difference in detectability and/or abundance could be relevant for tourism management, as visitors want to see many animals and prefer close-up experiences (Scholtz, Kruger \& Saayman, 2013). At the same time, a certain degree of road/traffic avoidance may be beneficial if road-associated mortality is reduced. Many studies suggest ways to mitigate barrier effect, for example through temporary and permanent traffic closured, or by limiting the number of visitors (Forman, 2005; Jaarsma, Langevelde \& Beunen, 2013). KNP authorities implemented several of these measures in the past (Ferreira \& Harmse, 1999), and these actions may have contributed to the habituation suggested in this study. Because impala are a key prey for many predators (Hayward \& Kerley, 2008), impala responses could influence predator distribution and behavior. In turn, predator changes may influence other ungulates, which could also be directly affected by roads and traffic. Future work would be necessary to explicitly evaluate impacts on the overall KNP community, but our study offers a first evaluation of how a model ungulate species is influenced by a widely used heterogeneous road-network in an African protected area.

\section{Acknowledgements}


We thank Scientific Services from Kruger National Park (SanParks), especially Marna Herbst for assistance. Adolf Botts and Steve M. Mepstead provided field assistance. Ramón Soriguer, the CarNe members (especially Eloy Revilla), Pelayo Acevedo, Roger Jovani and three anonymous reviewers provided useful comments on previous versions of this manuscript. MGS acknowledges funding from the Spanish Severo Ochoa Program (SEV-2012-0262) and a Juan de la Cierva postdoctoral fellowship (JCI-2011-09158).

\section{Literature cited}

Alves, C. \& Bager, A. (2013). Review of the factors undelying the mechanisms and effects of roads on vertebrates. Oecologia Aust. 17, 208-221.

Bulova, S.J. (1994). Ecological correlates of population and indivitual variation in atipredator behavior of two of desert lizards. Copeia 4, 980-992.

Carr, L.W. \& Fahrig, L. (2001). Effect of road traffic on two amphibian species of differing vagility. Conserv. Biol. 15, 1071-1078.

Ciuti, S., Northrup, J.M., Muhly, T.B., Simi, S., Musiani, M., Pitt, J.A. \& Boyce, M.S. (2012). Effects of humans on behaviour of wildlife exceed those of natural predators in a landscape of fear. PLoS One 7, e50611.

St. Clair, C.C. \& Forrest, A. (2009). Impacts of vehicle traffic on the distribution and behaviour of rutting elk, Cervus elaphus. Behaviour 146, 393-413.

Cole, E.K., Pope, M.D. \& Anthony, R.G. (1997). Effects of road management on movement and survival of Roosevelt elk. J. Wildl. Manage. 61, 1115-1126.

Conover, M.R., Pitt, W.C., Kessler, K.K., DuBow, T.J. \& Sanborn, W.A. (1995). Review of human injuries, illnesses, and economic losses caused by wildlife in the United States. Wildl. Soc. Bull. 23, 407-414.

Creel, S., Fox, J.E., Hardy, A., Sands, J., Garrott, B. \& Peterson, R.O. (2002). Snowmobile activity and glucocorticoid stress responses in wolves and elk. Conserv. Biol. 16, 809814.

D’Amico, M., Périquet, S., Román, J. \& Revilla, E. (in press). Road avoidance responses determine the impact of heterogeneous road-networks at regional scale. J. Appl. Ecol. Doi: 10.1111/1365-2664.12572

D’Amico, M., Román, J., de los Reyes, L. \& Revilla, E. (2015). Vertebrate road-kill patterns in Mediterranean habitats: Who, when and where. Biol. Conserv. 191, 234-242. 
D’Amico, M., Rouco, C., Russell, J.C., Román, J. \& Revilla, E. (2013). Invaders on the road: synanthropic bird foraging along highways. Oecologia Aust. 17, 86-95.

Dumont, F., Pasquaretta, C., Réale, D., Bogliani, G. \& von Hardenberg, A. (2012). Flight initiation distance and starting distance: biological effect or mathematical artefact? Ethology 118, 1051-1062.

Fahrig, L. \& Rytwinski, T. (2009). Effects of roads on animal abundance: an emperical review and synthesis. Ecol. Soc. 14, 21-41.

Ferreira, S.L.A. \& Harmse, A.C. (1999). The social carrying capacity of Kruger National Park, South Africa: policy and practice. Tour. Geogr. an Int. J. Tour. space, place Environ. 1, 325-342.

Forman, R.T.T. (2005). Good and bad places for roads: effects of varying road and natural pattern on habitat loss, degradation, and fragmentation. In International Conference on Ecology and Transportation: 164-174. Irwin, C., Garrett, P. \& McDermott, K. (Eds). . North Carolina, US.

Forman, R.T.T. \& Alexander, L.E. (1998). Roads and their major ecological effects. Annu. Rev. Ecol. Sist. 29, 207-231.

Gagnon, J.W., Theimer, T.C., Dodd, N.L., Boe, S. \& Schweinsburg, R.E. (2007). Traffic volume alters elk distribution and highway crossings in Arizona. J. Wildl. Manage. 71, 2318-2323.

Gertenbach, W.P.D. (1983). Landscapes of the Kruger National Park. Koedoe 26, 9-121.

Grilo, C., Sousa, J., Ascensão, F., Matos, H., Leitão, I., Pinheiro, P., Costa, M., Bernardo, J., Reto, D., Lourenço, R., Santos-Reis, M. \& Revilla, E. (2012). Individual spatial responses towards roads: implications for mortality risk. PLoS One 7, e43811.

Hayward, M.W. \& Kerley, G.I.H. (2008). Prey preferences and dietary overlap amongst Africa's large predators. S. Afr. J. Wildl. Res. 38, 93-108.

Herrero, S., Smith, T., DeBruyn, T.D., Gunther, K. \& Matt, C.A. (2005). From the field: brown bear habituation to people - safety, risks, and benefits. Wildl. Soc. Bull. 33, 362 373.

Hubbard, C.K. \& Nielsen, R.D. (2009). White-tailed deer attacking humans during the fawning season: a unique human-wildlife conflict on a university campus. HumanWildlife Conflicts 3, 129-135.

IUCN SSC Antelope Specialist Group. (2008). Aepyceros melampus. The IUCN Red List of Threatened Species. (Online DOI: 10.2305/IUCN.UK.2008.RLTS.T550A1306

0305.en) Jaarsma, C.F.R., Langevelde, F.F. Van \& Beunen, R.R. (2013). Landscape ecology and rural roads: traffic calming for improving both landscape and wildlife? Ekologia 32, $352-360$. 
Jaeger, J.A.G., Bowman, J., Brennan, J., Fahrig, L., Bert, D., Bouchard, J., Charbonneau, N., Frank, K., Gruber, B. \& von Toschanowitz, K.T. (2005). Predicting when animal populations are at risk from roads: an interactive model of road avoidance behavior. Ecol. Modell. 185, 329-348.

Knapp, K.K. (2004). Results of recent deer-vehicle crash information clearinghouse activities. In Proceedings of the 2003 International Conference on Ecology and Transportation: 385-389. Irwin, C.L., Nelson, D. \& McDermott, K.P. (Eds). . Raleigh, US.

KNP Scientific Services. (2015). Kruger National Park: Biodiversity Statistics [WWW Document]. KNP Sci. Serv. URL http://www.sanparks.org/parks/kruger/conservation/scientific/ff/biodiversity_statistics.ph $\mathrm{p}$

Laundré, J.W., Hernández, L. \& Altendorf, K.B. (2001). Wolves, elk, and bison: reestablishing the "landscape of fear" in Yellowstone National Park, U.S.A. Can. J. Zool 79, 1401-1409.

Laurance, W.F., Clements, G.R., Sloan, S., O’Connell, C.S., Mueller, N.D., Goosem, M., Venter, O., Edwards, D.P., Phalan, B., Balmford, A., Van Der Ree, R. \& Arrea, I.B. (2014). A global strategy for road building. Nature 8-13.

Laurance, W.F., Croes, B.M., Tchignoumba, L., Lahm, S. a., Alonso, A., Lee, M.E., Campbell, P. \& Ondzeano, C. (2006). Impacts of roads and hunting on Central African rainforest mammals. Conserv. Biol. 20, 1251-1261.

Lunde, E.T. (2013). Assessing the effect of roads on impala (Aepyceros melampus) stress levels using faecal glucocorticoid metabolites. Trondheim, Norwegian University of Science and Technology.

Malo, J.E., Acebes, P. \& Traba, J. (2011). Measuring ungulate tolerance to human with flight distance: a reliable visitor management tool? Biodivers. Conserv. 20, 3477-3488.

McGregor, R.L., Bender, D.J. \& Fahrig, L. (2008). Do small mammals avoid roads because of the traffic? J. Appl. Ecol. 45, 117-123.

Meisingset, E.L., Loe, L.E., Brekkum, Ø., Van Moorter, B. \& Mysterud, A. (2013). Red deer habitat selection and movements in relation to roads. J. Wildl. Manage. 77, 181-191.

Merriam, G., Kozakiewicz, M., Tsuchiya, E. \& Hawley, K. (1989). Barriers as boundaries for metapopulations and demes of Peromyscus leucopus in farm landscapes. Landsc. Ecol. 2, 227-235.

Mtui, E.K. (2014). Road constraints on impala (Aepyceros melampus) behavior. Norwegian University of Science and Technology.

Mulero-Pázmány, M., Stolper, R., van Essen, L.D., Negro, J.J. \& Sassen, T. (2014). Remotely piloted aircraft systems as a rhinoceros anti-poaching tool in Africa. PLoS One $\mathbf{9}$, e83873. 
Ndibalema, V.G., Mduma, S., Stokke, S. \& Røskaft, E. (2007). Relationship between road dust and ungulate density in Serengeti National Park, Tanzania. Afr. J. Ecol. 46, 547555.

Negrões, N., Revilla, E., Fonseca, C., Soares, A.M.V.., Jácomo, A.T.A. \& Silveira, L. (2011). Private forest reserves can aid in preserving the community of medium and large-sized vertebrates in the Amazon arc of deforestation. Biodivers. Conserv. 20, 505-518.

Newmark, W.D., Boshe, J.I., Sariko, H.I. \& Makumbule, G.K. (1996). Effects of a highway on large mammals in Mikumi National Park, Tanzania. Afr. J. Ecol. 34, 15-31.

Papaioannou, H.I. \& Kati, V.I. (2007). Current status of the Balkan chamois (Rupicapra rupicapra balcanica) in Greece: implications for conservation. Belg. J. Zool. 137, 33-39.

Papouchis, C.M., Singer, F.J. \& Sloan, W.B. (2001). Responses of desert bighorn sheep to increased human recreation. J. Wildl. Manage. 65, 573-582.

Périquet, S., Valeix, M., Loveridge, A.J., Madzikanda, H., Macdonald, D.W. \& Fritz, H. (2010). Individual vigilance of African herbivores while drinking: the role of immediate predation risk and context. Anim. Behav. 79, 665-671.

Pienaar, U. de V. (1969). Predator-prey relationships amongst the larger mammals of the Kruger National Park. Koedoe 12, 108-176.

Ribeiro, J.R. \& Diggle, P.J. (2001). geoR: A package for geostatistical analysis. R-NEWS 1, 14-18.

Sanparks. (2014). SanParks data repository [WWW Document]. URL http://dataknp.sanparks.org/sanparks/style/skins/sanparks/index.jsp

Scholtz, M., Kruger, M. \& Saayman, M. (2013). Understanding the reasons why tourists visit the Kruger National Park during a recession. Acta Comer. 13, 9.

Setsaas, T.H., Holmern, T., Mwakalebe, G., Stokke, S. \& Røskaft, E. (2007). How does human exploitation affect impala populations in protected and partially protected areas? A case study from the Serengeti ecosystem, Tanzania. Biol. Conserv. 136, 563-570.

Stankowich, T. (2008). Ungulate flight responses to human disturbance: a review and metaanalysis. Biol. Conserv. 141, 2159-2173.

Thomas, L., Buckland, S.T., Burnham, K.P., Anderson, D.R., Jeffrey, L., Borchers, D.L., Strindberg, S., El-shaarawi, A.H. \& Piegorsch, W.W. (2002). Distance sampling. In Encyclopedia of Environmetrics: 544-552. El-Shaarawi, A.H. \& Piegorsch, W.W. (Ed). Chichester, John Wiley \& Sons, Ltd.

Trombulak, S.C. \& Frissell, C. a. (2000). Review of ecological effects of roads on terrestrial and aquatic communities. Conserv. Biol. 14, 18-30.

Vos, A.C.C. \& Chardon, J.P. (1998). Effects of habitat fragmentation and road density on the distribution pattern of the moor frog Rana arvalis. J. Appl. Ecol. 35, 44-56. 
Wilmers, C.C., Crabtree, R.L., Smith, D.W., Murphy, K.M. \& Getz, W.M. (2003). Trophic facilitation by introduced top predators: grey wolf subsidies to scavengers in Yellowstone National Park. J. Anim. Ecol. 72, 909-916.

\section{Figures}

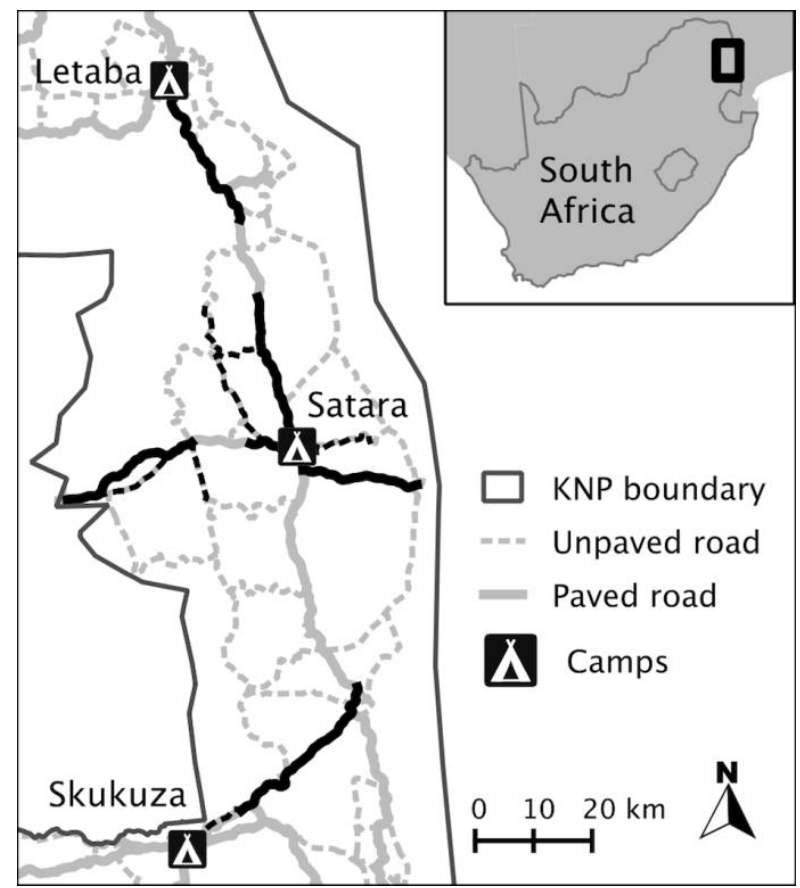

Figure 1. Study area, central Kruger National Park. Surveyed transects indicated by black lines (solid lines for paved roads, dashed lines for unpaved roads).

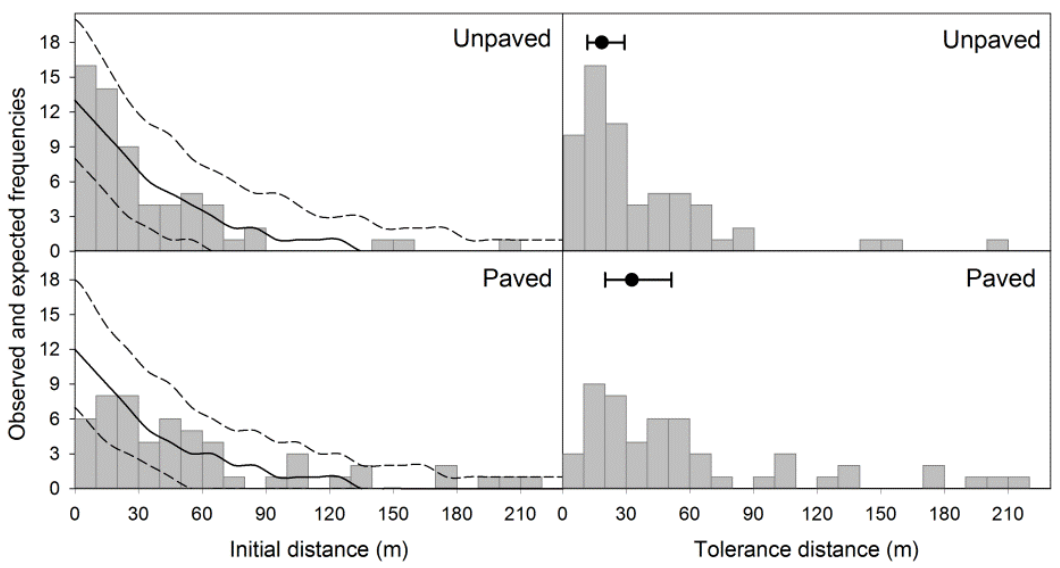

Figure 2. Observed initial distances (grey bars left panels) and tolerance distances (grey bars right panels) of impala Aepyceros melampus in unpaved and paved roads at Kruger National Park. The back lines on the left panels indicate the expected median (solid line) and 95\% 
confidence intervals (dashed lines) frequencies under a null model that assumes impala are randomly distributed in relationship to the road and detectability decreases following a negative exponential curve. On the right panel the black symbols with error bars are the mean and $95 \%$ CI tolerance distances predicted by a linear mixed effects regression model that included herd size as a covariate and transect identifier, date and ecozone as random effects to control for potential differences in detectability across areas.

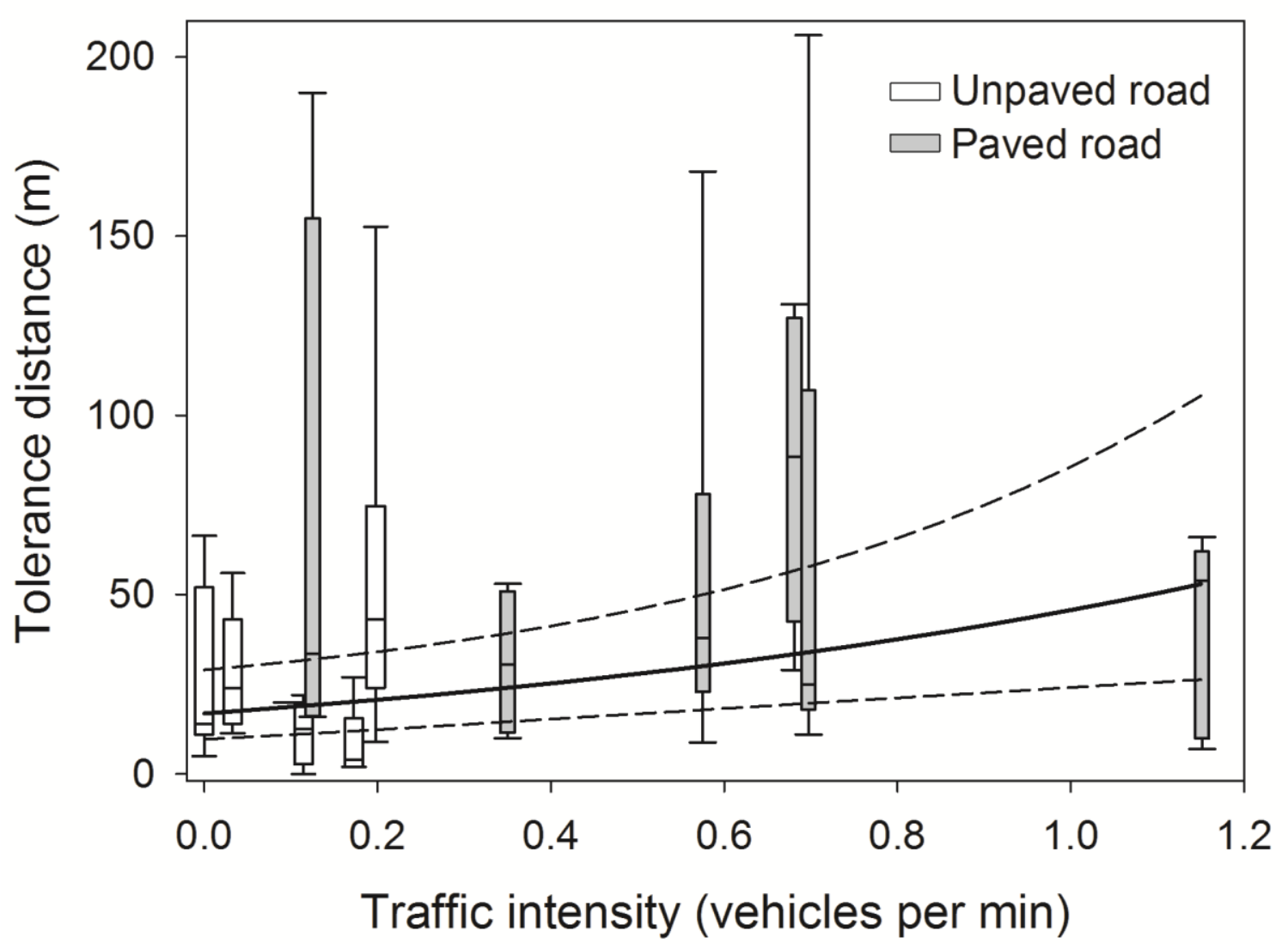

Figure 3. Observed (boxes) and predicted (lines) tolerance distances of impala Aepyceros melampus in response to estimated traffic intensity in Kruger National Park. Boxes indicate the $25 \%, 50 \%$ and $75 \%$ quantiles of observed distances (whiskers are $10 \%$ and $90 \%$ quantiles). Gray bars represent paved roads, white bards unpaved roads. The solid line is the predicted relationship from a mixed effects regression model including herd size as a covariate and transect identifier, date and ecozone as random effects to control for potential 
differences in detectability across areas. Dashed lines represent the 95\% confidence intervals of the predicted relationship. 